\title{
PEMBUATAN DAN DIGITALISASI BATIK TULIS MADURA PADA UKM BATIK BANGKALAN
}

\author{
Indah Agustien Siradjuddin, M. Kautsar Sophan, Arik Kurniawati, Rima Triwahyuningrum \\ Teknik Informatika, Universitas Trunojoyo Madura \\ E-mail: indah.siradjuddin@trunojoyo.ac.id
}

\begin{abstract}
ABSTRAK
Batik Madura dikenal akan jenis batik tulis Madura yang memiliki motif batik dan warna batik yang unik. Keseluruhan produksi batik tulis Madura ini dilakukan secara manual, mulai dari desain batik, menggambar batik pada kain, mencanting, fiksasi, pewarnaan, dan lain-lain. Proses manual inilah yang tetap menjaga keaslian batik tulis Madura. Hanya saja, kain batik yang dihasilkan pada batik tulis Madura ini, tidak menghasilkan pola yang simetris ketika kain batik dibuat menjadi sebuah pakaian. Motif-motif yang terdapat pada pakaian yang berasal dari kain batik tulis Madura, tidak membentuk pola yang simetris. Oleh karena itu diperlukan upaya agar motif-motif yang dibuat oleh pengrajin batik, dapat membentuk pola simetris pada suatu pakaian. Kegiatan pengabdian yang diusulkan adalah pembuatan motif batik tulis Madura, agar pakaian yang dihasilkan menampilkan pola simetris, dengan bantuan perangkat lunak. Tahap pertama yang dilakukan adalah pembuatan mal atau template pakaian yang akan dibuat, penyusunan mal ini pada desain kain batik, penyusunan motif-motif batik pada kain sehingga sesuai dengan mal pakaian yang telah ada.
\end{abstract}

Kata kunci: Batik tulis, motif batik, mal pakaian, simetris.

\section{PENDAHULUAN}

Batik merupakan salah satu budaya Indonesia yang mulai mendunia, dan telah dipatenkan menjadi produk seni budaya Indonesia pada tahun 2009 oleh UNESCO. Batik Madura adalah salah satu batik di Indonesia, yang terkenal akan pola dan warnanya yang unik. Batik Madura semakin diminati oleh para wisatawan semenjak akses menuju pulau Madura semakin mudah, yaitu dengan dibangunnya Jembatan Suramadu [1]-[3].

Batik Madura dikenal akan batik tulisnya. Seluruh proses pada pembuatan batik tulis Madura ini, dilakukan secara manual, mulai dari pembuatan motif sampai dengan pewarnaan. Bahkan terdapat beberapa batik yang memiliki pewarnaan yang unik, yaitu Batik Gentong [4], ataupun pewarnaan alami, yaitu pewarnaan yang berasal dari bahan-bahan alam, yaitu ekstrak tumbuhan. Harga batik tulis inipun beragam mulai dari harga dibawah seratus ribu rupiah, sampai dengan jutaan. Dengan keseluruhan proses secara manual ini, dapat menjaga keaslian batik tulis Madura, sehingga tetap dapat menarik para kolektor batik ataupun peminat batik Madura.

UKM Peri Kecil merupakan salah satu UKM yang berada di Bangkalan-Madura. UKM ini tetap menjaga konsistensi akan pembuatan batik tulis Madura. UKM ini telah dikenal oleh wisatawan domestik, dan mulai dikenal oleh para wisatawan asing. Karena selain menjual kain batik tulis Madura, pakaian, dan souvenir yang berasal dari batik tulis, UKM ini juga menyediakan tempat untuk belajar mencanting dan mewarnai batik, sehingga kegiatan ini dapat menarik wisatawan asing untuk lebih mengenal batik tulis Madura [5], [6], seperti yang ditunjukkan pada Gambar 1.
UKM Peri Kecil, dan UKM Wisma Anisa, bersama tim pengabdian juga telah turut serta dalam kegiatan pameran internasional yang berada di dalam negeri, yaitu Trade Expo Indonesia 2016, seperti yang ditunjukkan pada Gambar 2. Pada kegiatan pameran ini, banyak pembeli asing yang tertarik dan membeli batik tulis Madura.

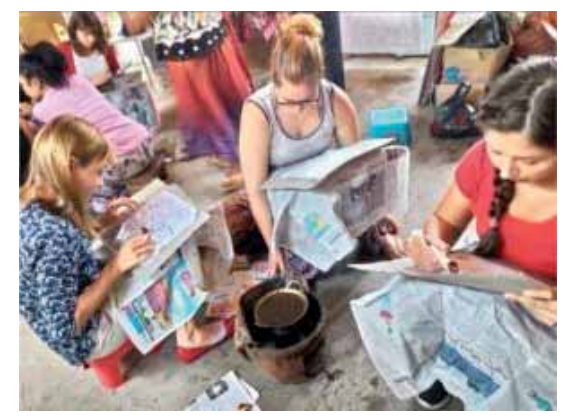

Gambar 1. Belajar membuat batik tulis Madura di UKM Batik Peri Kecil

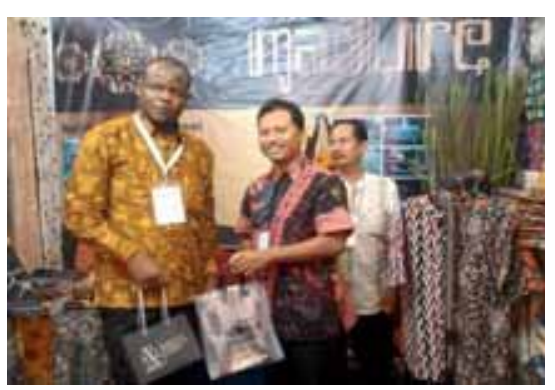

Gambar 2. Kegiatan Trade Expo Indonesia 2016. 


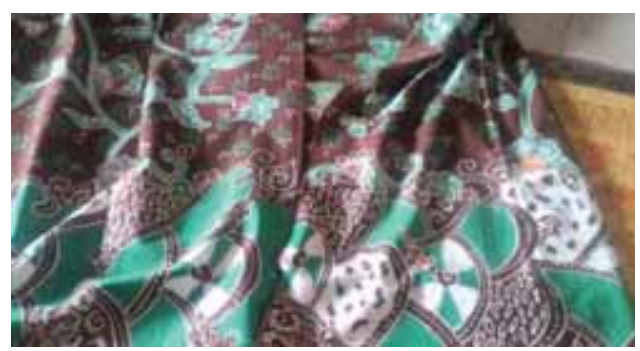

Gambar 3. Kain Batik Tulis Madura yang tidak simetris.

Bahkan pada kegiatan pameran ini juga, UKM berkesempatan untuk coba menjajaki keinginan para calon pembeli, mulai dari model pakaian, lebar kain batik, ukuran pakaian, dan lain-lain.

Disamping kelebihan-kelebihan yang dimiliki oleh batik tulis Madura, salah satu kekurangan yang dimiliki oleh kain batik Madura adalah ketidaksimetrisan pola yang dihasilkan, ketika kain batik Madura ini dibuat dalam bentuk baju. Contoh kain batik Madura yang tidak dapat membentuk pola baju yang simetris, dapat dilihat pada Gambar 3 .

Oleh karena itu tim pengabdian membuat suatu sistematika pembuatan batik tulis Madura agar motif pada kain batik menjadi pola yang simetris pada sebuah pakaian. Terdapat beberapa tahapan yang terdapat pada sistematikan yang dibuat oleh tim pengabdi, yaitu digitalisasi motif batik, pembuatan mal baju beserta ukuran yang diinginkan, penyusunan motif pada mal yang sudah disusun.

\section{DIGITALISASI MOTIF BATIK}

Tahap pertama yang terdapat pada mekanisme pembuatan motif batik yang diusulkan oleh tim pengabdi adalah digitalisasi motif Batik. UKM Peri kecil memiliki atau menyimpan motif-motif batik yang telah dibuat dan digunakan sebelumnya, pada media kertas, seperti yang ditunjukkan pada Gambar 4.

Pembuatan dan penyimpanan motif batik pada kertas ini dilakukan agar untuk pembuatan kain batik selanjutnya dapat mencontoh motif yang sudah dibuat sebelumnya. Hanya saja, penyimpanan motif batik ini terlalu berisiko, karena kertas mudah rusak, sobek, dan motif yang ada tidak dapat diolah ataupun diperbaiki, tanpa merusak motif yang sudah ada.

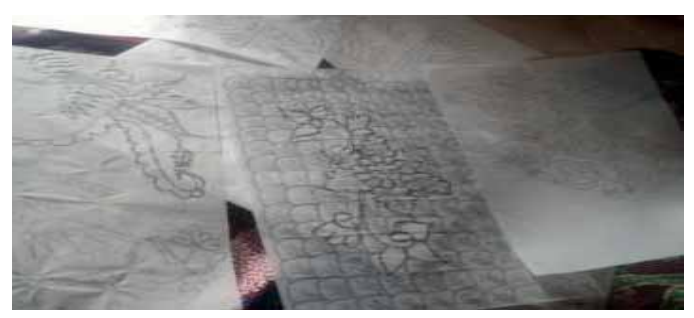

Gambar 4. Motif batik pada kertas
Oleh karena itu tahapan pertama adalah digitalisasi motif batik. Proses digitalisasi ini tidak hanya memindahkan media penyimpanan dari media kertas menjadi media dokumen computer, misalkan foto yang berbentuk ,jpgee, ,bmp ${ }^{\text {ee }}$, dll, akan tetapi lebih dari itu. Hasil digitalisasi adalah file gambar berupa vector. Dengan file gambar berupa vector yang berisi motif batik, maka gambar yang dihasilkan memiliki resolusi tinggi, dapat diolah, diperbesar, diperkecil, diperbaiki, dan lain-lain dengan kualitas gambar yang jauh lebih bagus dari pada gambar berupa foto.

Terdapat beberapa langkah yang harus dilakukan untuk proses digitalisasi ini (dengan menggunakan perangkat lunak Corel Draw), antara lain:

1. Siapkan foto atau hasil scan dari motif batik yang akan digitalisasi. Contoh hasil foto ini dapat dilihat pada Gambar 5.

2. Pembuatan motif dengan cara menjiplak setiap garis lengkung ataupun obyek pada foto. Hal ini dilakukan dengan menggunakan tool pada Corel Draw. Contoh jiplak motif pada foto, dapat dilihat pada Gambar 6 .

3. Lakukan untuk semua garis ataupun obyek pada motif batik.

Hasil digitalisasi foto motif batik pada Gambar 5, dapat dilihat pada Gambar 7.

Proses digitalisasi menghasilkan file gambar dalam bentuk vector, sehingga memiliki kualitas yang sangat bagus. Dengan gambar berbentuk vector ini, maka motif batik dapat diperbesar, diperbaiki, diberi tambahan, diperkecil, dan lain-lain, dan tetap menghasilkan kualitas gambar yang sangat bagus. Hasil digitalisasi ini dapat disimpan dan digunakan sewaktu-waktu untuk pembuatan kain batik tulis Madura selanjutnya.

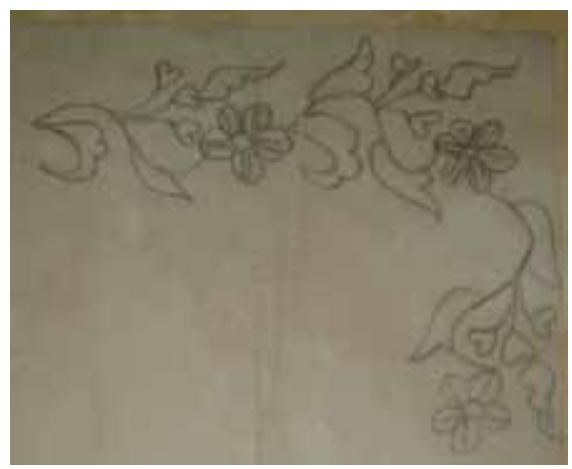

Gambar 5. Foto motif batik yang akan didigitalisasi

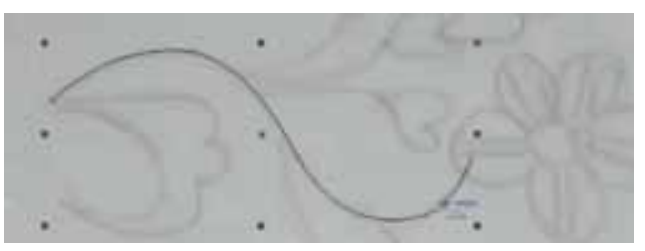

Gambar 6. Menjiplak motif batik dari foto batik 


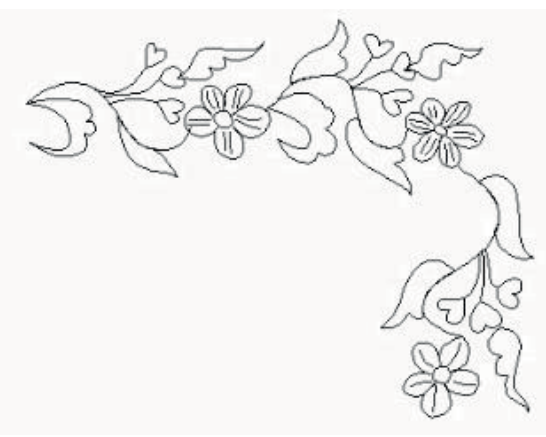

Gambar 7. Hasil digitalisasi.

\section{PEMBUATAN MAL BAJU}

Tahap kedua dari sistematika yang diusulkan oleh tim pengabdi adalah pembuatan mal baju dengan ukuran yang tepat ke dalam Corel Draw.

Contoh Mal baju yang telah dibuat dapat dilihat pada Gambar 8 dan Gambar 9.

Mal baju dibuat terlebih dahulu sesuai dengan ukuran yang diinginkan, apakah XL, L, M, ataupun S. Mal baju inilah yang akan disusun pada kain batik yang berukuran $2 \times 1.2 \mathrm{~m}$. Dengan penyusunan mal baju pada kain batik akan membuat para pengrajin batik atau UKM batik dapat meletakkan motif batik, agar baju batik yang dihasilkan menampilkan motif batik yang simetris.

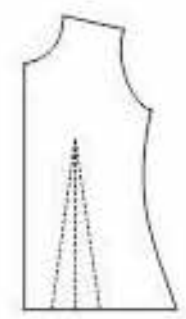

Depan

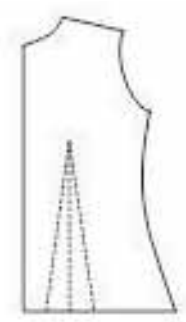

Belakang

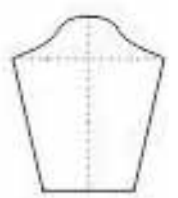

Tangan
Gambar 8. Mal baju wanita

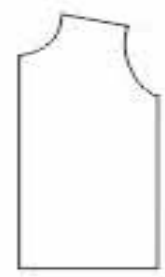

Depan

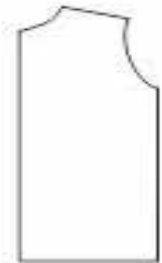

Belakang

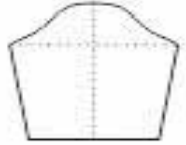

Tangan
Gambar 9. Mal baju laki-laki

\section{PENYUSUNAN MOTIF BATIK PADA MAL BAJU DAN TEMPLATE KAIN}

Tahap terakhir pada sistematika yang diusulkan tim pengabdi ini adalah penyusunan motif batik pada mal baju dan template kain. Motif batik yang digunakan adalah motif-motif yang sudah didigitalisasi pada proses sebelumnya, ataupun motif-motif yang telah dibuat secara langsung pada Corel Draw.

Langkah-langkah yang dilakukan untuk penyusunan motif batik ini antara lain:

1. Pembuatan template kain yang sesuai dengan ukuran kain batik pada umumnya, yaitu $2 \times 1.2$ meter. Pada template kain batik inilah, motif-motif yang sudah dibuat sebelumnya disusun.

2. Jika ingin membuat batik yang memiliki motif pinggiran batik, susun terlebih dahulu motif pinggiran batik, seperti yang terlihat pada Gambar 10.

3. Susun motif-motif batik, untuk mengisi kain bagian dalam, seperti yang ditunjukkan pada Gambar 11.

4. Penyusunan mal baju, agar tepat dengan motif yang telah disusun. Dengan penyusunan mal baju yang tepat, maka baju yang dihasilkan akan menampilkan motif batik secara simetris pada pakaian batik. Contoh mal baju dan motif batik dapat dilihat pada Gambar 12. Pola

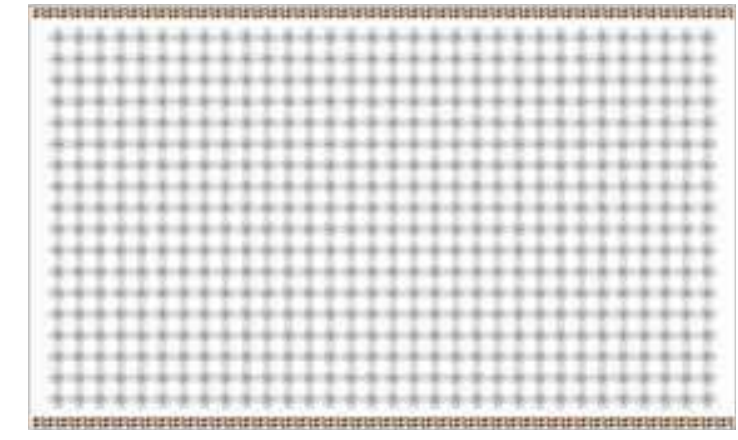

Gambar 11. Penyusunan motif pada posisi tengah kain batik

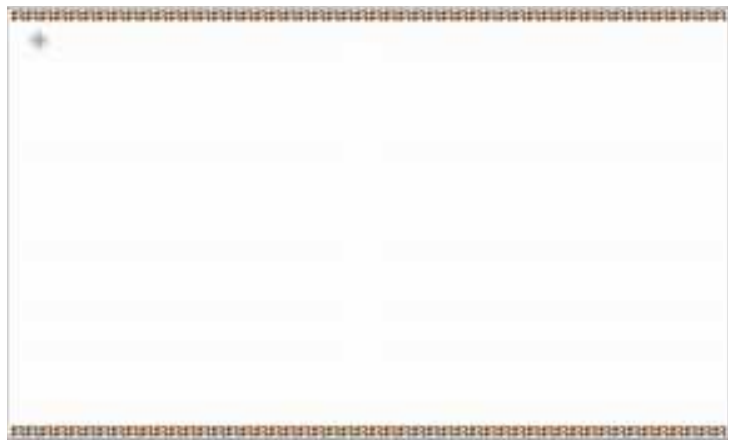

Gambar 10. Penyusunan motif pinggiran batik 
baju yang dihasilkan pada kain batik tersebut, dicetak dengan menggunakan kertas berukuran A4, sehingga akan dihasilkan cetakan lebih dari 20 kertas A4. Kertas-kertas ini digunakan sebagai template motif untuk kain. Sehingga pengrajin hanya meniru sesuai dengan urutan kertas yang telah dicetak.

\section{KESIMPULAN}

UKM-UKM Batik tulis Madura memiliki banyak potensi, karena para UKM ini saling berkompetisi dan bekerja sama untuk menghasilkan karya batik yang asli, memiliki karya seni tinggi, dan menciptakan kreasi-kreasi baru pada batik tulis yang dihasilkan. Hanya saja batik tulis yang dihasilkan masih belum dapat menampilkan pola motif batik yang simetris ketika kain batik tersebut dibuat menjadi pakaian. Oleh karena itu tim pengabdi mengusulkan mekanisme yang terdiri dari tiga langkah utama agar dapat menampilkan pola motif batik yang simetris pada pakaian. Selain pola yang simetris ini, hasil dari mekanisme yang diusulkan tim pengabdi adalah, digitalisasi motif batik. Dengan digitalisasi ini, maka pengrajin batik dapat menyimpan hasil karya mereka dalam file computer dengan kualitas high definition, sehingga dapat digunakan untuk pembuatan kain batik selanjutnya.

\section{DAFTAR PUSTAKA}

"Di Pasar Batik Madura Ini, Wisatawan Bisa Langsung Membeli Batik Ke Pengrajin.” [Online]. Available: http://travel.akurat.co//id-10517-read-di-pasarbatikmadura-ini-wisatawan-bisa-langsung-membeli-batikke-pengrajin. [Accessed: 04-Oct-2017].

"Semakin Asyik Berburu Batik Tulis di Pasar Wisata Bangkalan,” Tempo, 01- Feb-2017. [Online]. Available: https://travel.tempo.co/read/870070/semakin-asyikberburu-batik-tulis-di-pasar-wisata-bangkalan. [Accessed: 04-Oct- 2017].

“Gelinjang Batik Gentongan Tanjungbumi, Bangkalan, Madura," suroboyolife, 20-Mar-2017. [Online]. Available: http://suroboyolife.com/gelinjang-batikgentongan-tanjungbumi-bangkalan- madura/. [Accessed: 04-Oct-2017].

"Batik |." [Online]. Available: http://io.trunojoyo.ac.id/batik/. [Accessed: 04-Oct-2017]. [6] "Have Fun With Batik|." [Online]. Available: http://io.trunojoyo.ac.id/have- funwith-batik/. [Accessed: 04-Oct - 2017]. 